\title{
Effect of Ozone, Clothing, Temperature, and Humidity on the Total OH Reactivity Emitted from Humans
}

Zannoni, Nora; Li, Mengze; Wang, Nijing; Ernle, Lisa; Bekö, Gabriel; Wargocki, Pawel; Langer, Sarka; Weschler, Charles J.; Morrison, Glenn; Williams, Jonathan

\section{Published in:}

Environmental Science and Technology

Link to article, DOI:

10.1021/acs.est.1c01831

Publication date:

2021

Document Version

Publisher's PDF, also known as Version of record

Link back to DTU Orbit

Citation (APA):

Zannoni, N., Li, M., Wang, N., Ernle, L., Bekö, G., Wargocki, P., Langer, S., Weschler, C. J., Morrison, G., \& Williams, J. (2021). Effect of Ozone, Clothing, Temperature, and Humidity on the Total OH Reactivity Emitted from Humans. Environmental Science and Technology, 55, 1361413624.

https://doi.org/10.1021/acs.est.1c01831

\section{General rights}

Copyright and moral rights for the publications made accessible in the public portal are retained by the authors and/or other copyright owners and it is a condition of accessing publications that users recognise and abide by the legal requirements associated with these rights.

- Users may download and print one copy of any publication from the public portal for the purpose of private study or research.

- You may not further distribute the material or use it for any profit-making activity or commercial gain

- You may freely distribute the URL identifying the publication in the public portal 


\title{
Effect of Ozone, Clothing, Temperature, and Humidity on the Total $\mathrm{OH}$ Reactivity Emitted from Humans
}

\author{
Nora Zannoni,* Mengze Li, Nijing Wang, Lisa Ernle, Gabriel Bekö, Pawel Wargocki, Sarka Langer, \\ Charles J. Weschler, Glenn Morrison, and Jonathan Williams
}

Cite This: Environ. Sci. Technol. 2021, 55, 13614-13624

Read Online

ACCESS | Lill Metrics \& More | 国 Article Recommendations | st Supporting Information

ABSTRACT: People influence indoor air chemistry through their chemical emissions via breath and skin. Previous studies showed that direct measurement of total $\mathrm{OH}$ reactivity of human emissions matched that calculated from parallel measurements of volatile organic compounds (VOCs) from breath, skin, and the whole body. In this study, we determined, with direct measurements from two independent groups of four adult volunteers, the effect of indoor temperature and humidity, clothing coverage (amount of exposed skin), and indoor ozone concentration on the total $\mathrm{OH}$ reactivity of gaseous human emissions. The results show that the measured concentrations of VOCs and ammonia adequately account for the measured total $\mathrm{OH}$ reactivity. The total $\mathrm{OH}$ reactivity of human emissions was primarily affected by ozone reactions with organic skin-

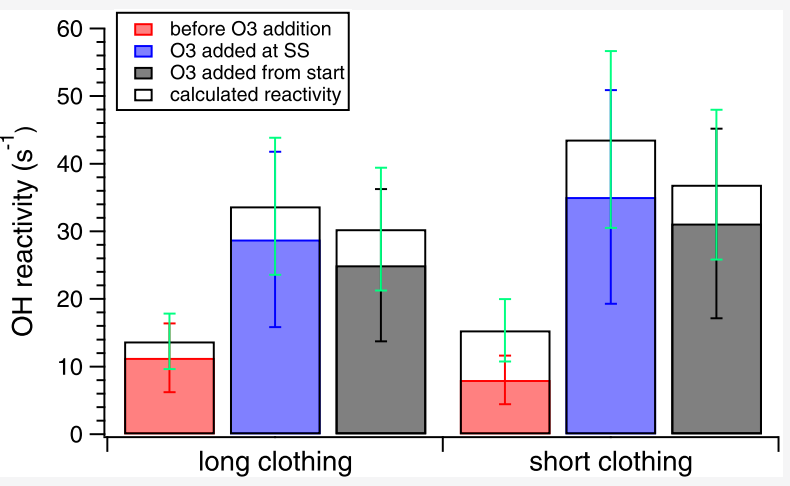
oil constituents and increased with exposed skin surface, higher temperature, and higher humidity. Humans emitted a comparable total mixing ratio of VOCs and ammonia at elevated temperature-low humidity and elevated temperature-high humidity, with relatively low diversity in chemical classes. In contrast, the total $\mathrm{OH}$ reactivity increased with higher temperature and higher humidity, with a larger diversity in chemical classes compared to the total mixing ratio. Ozone present, carbonyl compounds were the dominant reactive compounds in all of the reported conditions.

KEYWORDS: indoor chemistry, volatile organic compounds, human skin emissions, indoor ozone, ozone deposition velocity

\section{INTRODUCTION}

On average, we spend $85-90 \%$ of our time indoors, ${ }^{1,2}$ that is, at home, in offices, and schools. While indoor environments afford some protection against outdoor ozone and fine particles, confined volume and limited ventilation can increase exposure to multiple volatile organic and inorganic compounds from indoor sources. ${ }^{3}$ Indoor air chemistry is influenced by the strength and nature of the indoor sources, the ventilation rate and quality of outdoor air, the ratio of exposed surfaces to volume of the space, and occurrence of natural light sources that drive photochemistry outdoors. ${ }^{4}$ In occupied environments, human beings and their associated activities such as cooking and cleaning represent the dominant source of gaseous and particulate emissions. ${ }^{5,6}$ Human beings emit numerous reactive volatile organic compounds (VOCs) through their breath and skin. ${ }^{7-10}$ The main VOCs reported from breath emissions of healthy individuals include hydrocarbons such as isoprene, alcohols, ketones, and compounds containing nitrogen and sulfur. ${ }^{11}$ Common skin VOCs include compounds directly emitted by the body as well as those resulting from oxidation of such compounds (e.g., 6-methyl-5hepten-2-one and geranyl acetone). In total, approximately 500 compounds have been identified as emissions from skin, compared to almost 900 identified in breath. ${ }^{7,12}$ Ozone $\left(\mathrm{O}_{3}\right)$, the main indoor oxidant, is also the main chemical sink of human emissions, although present at only $10-70 \%$ of the outdoor levels due to losses (reaction) during the building envelope penetration and on indoor surfaces. ${ }^{13}$ Ozone deposition velocities have been calculated for materials used in building furnishings, ${ }^{14-16}$ occupied environments, ${ }^{8,17}$ aircrafts interiors, ${ }^{18}$ skin, ${ }^{19}$ hair, ${ }^{20}$ and clothing. ${ }^{18,19,21}$ Values can range from $<1$ to $>20 \mathrm{~m} / \mathrm{h},{ }^{22}$ but the central tendency for areaaveraged surfaces indoors is about $1.4 \mathrm{~m} / \mathrm{h}$. The largest reported deposition velocities were associated with human skin, soiled hair, and clothing. Adult human skin has a large surface area $\left(1.5-2.0 \mathrm{~m}^{2}\right)$ and, due to secretions from glands across the body, it is covered with proteins and lipids such as fatty acids, triglycerides, cholesterol, and squalene $\left(\mathrm{C}_{30} \mathrm{H}_{50}\right){ }^{23}$ The latter contributes roughly to $50 \%$ of the $\mathrm{C}=\mathrm{C}$ bonds

Received: March 20, 2021

Revised: September 8, 2021

Accepted: September 9, 2021

Published: September 30, 2021

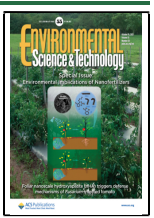


available for $\mathrm{O}_{3}$ reactions. ${ }^{20}$ Squalene reacts rapidly with $\mathrm{O}_{3}$ generating first-generation products including ketones such as acetone $\left(\mathrm{C}_{3} \mathrm{H}_{6} \mathrm{O}\right)$, 6-methyl-5-hepten-2-one (6-MHO, $\left.\mathrm{C}_{8} \mathrm{H}_{14} \mathrm{O}\right)$, and geranyl acetone $\left(\mathrm{C}_{13} \mathrm{H}_{22} \mathrm{O}\right)$. Further $\mathrm{O}_{3}$ reactions with the primary products lead to secondary products such as additional acetone, 4-oxopentanal (4-OPA, $\mathrm{C}_{5} \mathrm{H}_{8} \mathrm{O}_{2}$ ), 1,4-butanedial $\left(\mathrm{C}_{4} \mathrm{H}_{6} \mathrm{O}_{2}\right)$, and levulinic acid $\left(\mathrm{C}_{5} \mathrm{H}_{8} \mathrm{O}_{3}\right)$. The generation of gas-phase products is dependent on environmental factors such as $\mathrm{O}_{3}$ concentration and relative humidity. $^{24}$

One of the most critical aspects for understanding indoor air chemistry and quality is a comprehensive knowledge of the VOCs present indoors and emitted by humans, ${ }^{25}$ as well as their reactivity and lifetime. A relatively new measurement, namely, the total hydroxyl radical $(\mathrm{OH})$ reactivity, ${ }^{26}$ allows direct assessment of the entire chemical budget of compounds that react with the $\mathrm{OH}$ radical. Coupled with measurements of individual VOCs, it can be used to determine how complete is the chemical characterization of reactive organic compounds in air. The total $\mathrm{OH}$ reactivity is defined as the total loss frequency of $\mathrm{OH}$, the inverse being the $\mathrm{OH}$ lifetime. Since the development of the concept of total $\mathrm{OH}$ reactivity as a "topdown" parameter, ${ }^{26}$ a number of instruments measuring $\mathrm{OH}$ reactivity have been deployed in a diverse set of outdoor environments, ${ }^{27-30}$ with the goal of investigating budgets of reactive VOCs as well as $\mathrm{OH}^{31}$ and $\mathrm{O}_{3}{ }^{32}$

The Indoor Chemical Human Emissions and Reactivity (ICHEAR) project aimed at quantifying VOC emissions and $\mathrm{OH}$ reactivity from adult volunteers exposed in groups of four in a controlled climate chamber. ${ }^{33}$ In Wang et al., ${ }^{34}$ we analyzed the $\mathrm{OH}$ reactivity of isolated breath and dermal emissions as well as whole-body emissions from volunteers of different age groups in the presence and absence of $\mathrm{O}_{3}$. We showed that the reactive VOCs budget was closed, that when $\mathrm{O}_{3}$ was present, "OH reactivity approximately doubled" with the increase due chiefly to unsaturated secondary products of $\mathrm{O}_{3}$-skin-oil chemistry (57\%), and that no significant difference was observed among different age groups. ${ }^{34}$ In this study, using results from a different set of experiments, we examine the effects of indoor $\mathrm{O}_{3}$ concentration, clothing, temperature, and relative humidity on the total $\mathrm{OH}$ reactivity of whole body emissions from experiments involving two different groups of adult volunteers.

\section{METHODS}

Experimental Design and Methods. The experiments were conducted in a $22.5 \mathrm{~m}^{3}$ stainless steel climate chambers at the Technical University of Denmark (DTU) as part of the ICHEAR project (Table S1). The focus of this research was on human bioeffluents, so other emission sources were minimized. The chamber was furnished with a table and four wire-meshed chairs, and measurements of the empty chambers were taken before volunteers entered to characterize background conditions. Prefiltered outdoor $\mathrm{O}_{3}$-free air was used to ventilate the chamber with an average air change rate (ACR) of $3.2 \mathrm{~h}^{-1}$. Mixing was ensured with two fans in the chamber, directed to the walls. The environmental conditions were either moderate temperature and low humidity (set points $25{ }^{\circ} \mathrm{C}$ and $25 \%$, respectively), or high temperature and high humidity (set points $31{ }^{\circ} \mathrm{C}$ and $65 \%$, respectively). Ozone was added into the supply air either before the start of the experiment, so that its concentration had reached steady state (SS) before the volunteers entered (short experimental days-morning only), or it was introduced into the chamber air after the human emitted volatile organic compounds reached steady state (long experimental days-morning and afternoon). Although the two scenarios result in identical steady-state ozone concentration with occupancy (around $35 \mathrm{ppb}$ ), they have different dynamics; when steady state is approached from an ozone-rich state more ozone-initiated chemistry occurs than when steady state is approached from an ozone-poor state. ${ }^{35}$ In the latter case, the volunteers left the chamber for a 10 min lunch break after $3 \mathrm{~h}$ of $\mathrm{O}_{3}$-free condition. Ozone generation commenced $10 \mathrm{~min}$ after they returned to the chamber for another $2.5 \mathrm{~h}$ exposure. The target $\mathrm{O}_{3}$ mixing ratio in the unoccupied chamber was $\sim 100 \mathrm{ppb}$, which resulted in a chamber level of $\sim 35 \mathrm{ppb}$ when four volunteers were present.

Two groups with young adult volunteers participated in the present experiments, originally termed as groups A1 and A2. ${ }^{31}$ Each group was composed of two females and two males being $\sim 25$ years old. They were asked to refrain from drinking alcohol and eating spicy food one day prior to and during the days of the experiments. The night before each experimental day they were washed with provided fragrance-free soap and shampoo; no shower was taken in the morning. During the experiments, they wore a provided set of new prewashed (fragrance-free detergent) and tumble-dried "long" or "short" clothing. "Long clothing" consisted of sweatpants, long-sleeve shirts, and calf socks, while "short clothing" consisted of shorts, $\mathrm{t}$-shirts, and ankle socks.

Separate experiments on $\mathrm{O}_{3}$ exposure (concentration at the inlet $\sim 100 \mathrm{ppb}, \mathrm{ACR} \sim 3.2 \mathrm{~h}^{-1}$ ) of clothing only were conducted with four clean t-shirts and four soiled (worn) $\mathrm{t}$ shirts, of the same type given to the volunteers. Soiled t-shirts were worn overnight and hung inside-out in the chamber. Detailed information on the experimental design is provided in Bekö et al. ${ }^{33}$

Total $\mathrm{OH}$ reactivity was measured using a custom-built comparative reactivity method (CRM) instrument previously deployed in multiple outdoor atmosphere measurement campaigns $^{32}$ and validated in a large inter-comparison exercise. $^{36}$ The $\mathrm{CRM}^{37}$ combines a glass flow reactor with a proton transfer reaction-quadrupole mass spectrometer (PTRQMS, Ionicon Analytik GmbH, Austria ${ }^{38}$ ) to measure the concentration of a reference compound normally not found in ambient or indoor air (here pyrrole, $\mathrm{C}_{4} \mathrm{H}_{5} \mathrm{~N}$ ), whose reaction rate with $\mathrm{OH}$ is known, and whose concentration can be unambiguously detected by PTR-MS $\left(\mathrm{C}_{4} \mathrm{H}_{5} \mathrm{NH}^{+}, \mathrm{m} / z 68\right)$. The PTR-MS was operated at standard conditions $\left(P_{\text {drift }}=2.2\right.$ mbar, $\mathrm{E} / \mathrm{N}=130 \mathrm{Td}, T_{\text {inlet }}=60^{\circ} \mathrm{C}$ ) to monitor $\mathrm{m} / z 68$ with a dwell time of $20 \mathrm{~s}$. A pressurized gas standard of pyrrole (Westfalen AG, Germany) was diluted in the flow reactor and the concentration, $C$, was measured under three sequential conditions: with clean air and dry $\mathrm{N}_{2}$ after photolysis $(C 1)$, after $\mathrm{OH}$ is generated (C2), with chamber air replacing clean air (C3). Hydroxyl radicals were generated in the glass flow reactor through photolysis of water vapor ( $\mathrm{Hg} \mathrm{UV}$ lamp emitting at $184.9 \mathrm{~nm}$ ). Assuming a pseudo-first-order kinetics regime inside the reactor ([pyrrole $] \gg[\mathrm{OH}])$, the $\mathrm{OH}$ reactivity $R_{\text {air }}$ was determined from pyrrole concentrations $C 1$, $C 2$, and $C 3$ with eq 1

$$
R_{\text {air }}=\frac{(C 3-C 2)}{(C 1-C 3)} \times k_{\text {pyrrole }+\mathrm{OH}} \times C 1
$$


where $k_{\text {pyrrole }+\mathrm{OH}}$ is the rate constant of the reaction between pyrrole and $\mathrm{OH}$ and equals $(1.20 \pm 0.16) \times 10^{-10} \mathrm{~cm}^{3}$ molecule $\mathrm{s}^{-1} \cdot{ }^{39,40}$ The concentration $C 1$ was quantified after each experiment using an $\mathrm{OH}$ scavenger. ${ }^{41}$ The $\mathrm{OH}$ scavenger used during the campaign was propane at a concentration $\sim 3.6 \times 10^{3} \mathrm{ppm}$ inside the reactor. The pyrrole mixing ratio $C 1$ measured when the reactor was wet with the $\mathrm{OH}$ scavenger was $59 \pm 15 \mathrm{ppb}$ (mean campaign value $\pm 1 \sigma$ ), and the pyrrole mixing ratio $C 1$ measured when the reactor was dry without any $\mathrm{OH}$ scavenger was $55 \mathrm{ppb}$. An automated system switched between clean air (to determine C2) and chamber air (to determine C3) every $5 \mathrm{~min}$. The data processing consists of a PTR-MS calibration with pyrrole at different levels of humidity, humidity correction on $\mathrm{C} 2$ to correct for $\mathrm{OH}$ recycling when humidity changed, $\mathrm{NO}_{x}$ and $\mathrm{O}_{3}$ corrections on $\mathrm{C} 3$ for $\mathrm{OH}$ recycling, reactivity calibration for deviation from pseudo-first-order kinetics with test gas having different $\mathrm{OH}$ rate coefficients, and dilution of the sampling flow into the flow reactor. All correction factors were determined experimentally. ${ }^{34,42}$ Correction for $\mathrm{NO}_{x}$ and $\mathrm{O}_{3}$ interference for recycling $\mathrm{OH}$ were not necessary as the $\mathrm{NO}$ concentration measured inside the chamber was $\sim 1 \mathrm{ppb}$ (corresponding to a change in reactivity $<3 \%$ ), and increasing concentrations of $\mathrm{O}_{3}(0-110 \mathrm{ppb})$ were tested and found not to interfere with the chamber CRM set-up. The resolution of the $\mathrm{OH}$ reactivity measurements was $1-10 \mathrm{~min}$, the limit of detection $(1 \sigma)$ was $\sim 5 \mathrm{~s}^{-1}$ and the quantified total uncertainty was $\sim 48 \%$. The total uncertainty was calculated as the propagated uncertainty on the pyrrole standard (10\%), on the rate constant of the reaction between pyrrole and $\mathrm{OH}$ (14\%), on the dilution of the sampled flow $(0.16 \%)$, on the corrections used (31\% for kinetics conditions, $29 \%$ for humidity), and on signal precision $(\sim 15 \%)$.

Ancillary measurements performed during the ICHEAR campaign and used in this study included: volatile organic compounds (VOCs) detected with a PTR-MS equipped with a time of flight detector ( $\mathrm{ToF})$, and with a fast gas chromatograph-mass spectrometer (fast GC-MS); carbon dioxide $\left(\mathrm{CO}_{2}\right)$ and ammonia $\left(\mathrm{NH}_{3}\right)$ detected with cavity ring-down spectroscopy (Picarro, G2401 and G2103, respectively), ozone $\left(\mathrm{O}_{3}\right)$, temperature and relative humidity $(\mathrm{RH}) .^{33,34,43}$

A common fluorinated ethylene propylene (FEP) inlet (OD $1 / 2$ in., length $5 \mathrm{~m}$ ) was installed in the chamber's air exhaust outlet and air was drawn (sampling flow $\sim 7 \mathrm{~L} \mathrm{~min}^{-1}$ ) to the sampling devices to measure VOCs, $\mathrm{OH}$ reactivity, and $\mathrm{CO}_{2}$ concentration. Background measurements of the supply air just before it entered the chamber were taken periodically before, during, and after each experiment. Ozone was measured from a separate inlet in the middle of the chamber, and the air temperature and humidity sensors were placed in the chamber.

PTR-ToF-MS (PTR-ToF-MS 8000, Ionicon Analytik $\mathrm{GmbH}$, Austria $^{38}$ ) was operated under standard conditions $\left(P_{\text {drift }}=2.2 \mathrm{mbar}, T_{\text {inlet }}=60{ }^{\circ} \mathrm{C}\right.$ and $\left.\mathrm{E} / \mathrm{N}=137 \mathrm{Td}\right)$ with $\mathrm{m} / z$ up to 450 (mass resolution 4000 at $96 \mathrm{amu}$ ). A certified gas standard mixture (Apel-Riemer Environmental Inc.) containing 14 compounds was used to calibrate the instrument during the campaign. Calibrations were performed at stepwise increasing concentrations at different humidity levels (10$80 \%)$. The sensitivity was generally not affected by humidity (below 10\% for most compounds, except for benzene and toluene, where sensitivity varied within $20 \%$ ). A humiditydependent sensitivity curve was derived and used to determine the concentrations of the species included in the calibration gas. A theoretical method was applied to determine the mixing ratios of the masses of the compounds not included in the gas standard. ${ }^{44}$ The time resolution of the measurements was $20 \mathrm{~s}$, the uncertainty was up to $11 \%$ for the compounds in the calibration mixture (including uncertainty derived from the humidity dependency), and $\sim 50 \%$ for those compounds not included in the calibration mixture.

The fast GC-MS instrument (SOFIA-System for Organic Fast Identification Analysis ${ }^{45}$ ) was equipped with a cryogenic pre-concentrator. A sampling volume of $20-40 \mathrm{~mL}$ was collected. A quartz particle filter impregnated with a $10 \% \mathrm{w} / \mathrm{w}$ solution of sodium thiosulfate was installed at the inlet to scrub $\mathrm{O}_{3}$. Calibrations were performed using a certified gas standard mixture (Apel-Riemer Environmental Inc.) containing 79 compounds. The time resolution of the measurements was 3 min, the limit of detection was $<25 \mathrm{ppt}$, and the uncertainty was $<10 \%$.

The time resolution of $\mathrm{CO}_{2}$ and $\mathrm{NH}_{3}$ was 2 s. Ozone was monitored with a 2B Technologies model 205 ozone monitor (2B Technologies, Boulder, CO) with a time resolution of $10 \mathrm{~s}$ (accuracy: $1.0 \mathrm{ppb}$ or $2 \%$ of reading). Air temperature and $\mathrm{RH}$ were monitored with Vaisala GMW90 (accuracy: temperature $\pm 0.5{ }^{\circ} \mathrm{C}$, $\mathrm{RH} \pm 2.5 \%$ below $60 \%$; Vaisala Corporation, Helsinki, Finland) connected to a HOBO UX120-006M 4channel analog data logger (Onset Computer Corporation, Bourne, MA) with a time resolution of $1 \mathrm{~min}^{33}$

Skin Wipes Samples. Skin wipes were collected from the volunteers' right forearm before and from the left forearm after each experiment. Pre-cleaned sterilized cotton pads wetted with 2-propanol were used to thoroughly wipe ( 7 strokes) a skin area of $100 \mathrm{~cm}^{2}$. Squalene $\left(\mathrm{C}_{30} \mathrm{H}_{50}\right)$ and pyroglutamic acid $\left(\mathrm{C}_{5} \mathrm{H}_{7} \mathrm{NO}_{3}\right)$ concentrations were determined in the collected samples through extraction with an organic solvent and analyzed by gas and liquid chromatography coupled with mass spectrometry GC/MS and LC/MS/MS.

$\mathrm{OH}$ Reactivity Budget. Volatile organic compounds and ammonia concentrations $\left(X_{i}\right)$ and their rate coefficients of reaction with $\mathrm{OH}\left(k_{i+\mathrm{OH}}\right)$ were used to determine the speciesspecific $\mathrm{OH}$ reactivity. The sum of species-specific $\mathrm{OH}$ reactivities for all measured compounds yields the summed calculated $\mathrm{OH}$ reactivity (eq 2 )

$$
R=\sum_{i} k_{i+\mathrm{OH}} \times X_{i}
$$

Table S2 lists the compounds used to calculate the reactivity. From the measured PTR-ToF-MS masses $(21-450 \mathrm{~m} / z)$, only masses above the instrumental limit of detection and known to be related to human emissions (higher mixing ratios detected from the occupied chamber in comparison with the unoccupied chamber) were selected to calculate their $\mathrm{OH}$ reactivity. The uncertainty of the calculated $\mathrm{OH}$ reactivity $(\sim 30 \%)$ was determined from the propagation of the uncertainty of the measured concentration $X_{i}(10-50 \%)$ and the error in the rate coefficient of the reaction between $i$ and $\mathrm{OH}\left(k_{i+\mathrm{OH}}, 10-100 \%\right)$. The comparison between the total measured $\mathrm{OH}$ reactivity and the calculated $\mathrm{OH}$ reactivity allows verification of whether all of the OH-reactive VOCs were identified and quantified. As discussed in Wang et al., ${ }^{34}$ the length and material of the sampling system used during the ICHEAR campaign differed from those used in previous experiments, ${ }^{8,35}$ and this may have led to sampling artifacts. Specifically, in the presence of ozone, adsorption of geranyl acetone on the main inlet FEP surface may have led to 


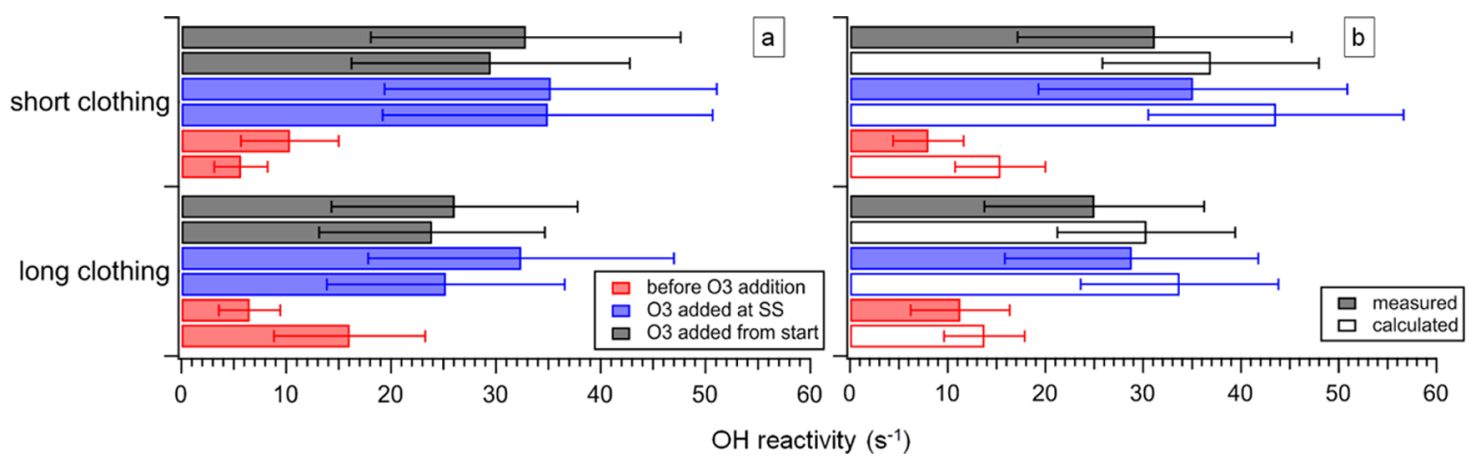

Figure 1. (a) Measured $\mathrm{OH}$ reactivity from occupant emissions at steady state. Experiments involved the same four adult volunteers occupying a chamber wearing long clothing or short clothing, under the same conditions on different days. Two replicates were done for the same condition with the same volunteers on different days $(n=2)$. Ozone was absent (red), introduced to the chamber when VOC reached SS (blue), or introduced to the chamber from the start of the experiment (black). (b) Measured (filled bars) and calculated (empty bars) OH reactivity from occupant emissions at steady state. Each bar corresponds to the mean among SS values between the two replicates conducted for each condition. Error bars indicate the method uncertainties ( $\sim 48 \%$ for measured reactivity, $\sim 30 \%$ for calculated reactivity). Steady-state values were determined during the last $15 \mathrm{~min}$ before occupants left the chamber.

consequent reactions with ozone, decreasing the measured steady-state concentration of geranyl acetone and increasing that of 6-MHO. This artifact would not affect the VOC budget analysis reported in this work as the $\mathrm{OH}$ reactivity and VOCs were measured with the same sampling system.

Ozone Deposition Velocities on Occupant Surfaces. The first-order rate constant for $\mathrm{O}_{3}$ loss by all mechanisms, $k_{\mathrm{d}}$ was calculated based on eq $3^{6}$

$$
k_{\mathrm{d}}=\lambda\left(\frac{C_{\mathrm{O}, \text { inlet }}}{C_{\mathrm{O} 3, \text { outlet }}}-1\right)
$$

where $C_{\mathrm{O} 3 \text {,inlet }}$ is the chamber inlet $\mathrm{O}_{3}$ mixing ratio, $C_{\mathrm{O} 3 \text {,outlet }}$ is the chamber outlet $\mathrm{O}_{3}$ mixing ratio, and $\lambda$ is the air change rate. For an occupied chamber, $\mathrm{O}_{3}$ loss is dominated by deposition to the occupants; in this case, the loss rate constant in eq 3 is equal to that associated with the occupant, $k_{\text {occ }}$. For experiments in which only clean or soiled t-shirts are present in the chamber, $\mathrm{O}_{3}$ loss is dominated by deposition to clothing and the removal rate constant is $k_{\text {cloth,only. Ozone removal }}$ associated with chamber surfaces was negligible compared to that on occupants or clothing surfaces $\left(k_{\text {chamber }}=0.15-0.17\right.$ $\left.\mathrm{h}^{-133,35}\right)$. For surface removal, each rate constant can be expressed as the product of a mass transfer coefficient (deposition velocity, $v$ ) and the area of the reactive surface, $A$, divided by the chamber volume, $V$. Therefore

$$
\lambda\left(\frac{C_{\mathrm{O} 3, \text { inlet }}}{C_{\mathrm{O} 3, \text { outlet }}}-1\right)_{\text {occupied }}=\frac{\nu_{\mathrm{occ}} A_{\mathrm{occ}}}{V}
$$

where the subscripts refer to occupants (occ). The deposition velocity to the four occupants, $\nu_{\text {occ }}$ can be solved directly from eq 4 using the total body surface area (BSA) of the participants calculated according to Du Bois and Du Bois ${ }^{46}\left(7.3 \mathrm{~m}^{2}\right.$ in agreement with the average BSA $1.9 \mathrm{~m}^{2}$ of a healthy adult ${ }^{47}$ ). For an experiment with clothing only (no occupants) in the chamber, $v_{\text {cloth,only }}$ can be solved directly from eq 5 , where $A_{\text {cloth,only }}$ is $0.7 \mathrm{~m}^{2}$ per medium-sized shirt times the number of shirts deployed in the chamber.

$$
\lambda\left(\frac{C_{\mathrm{O} 3, \text { inlet }}}{C_{\mathrm{O} \text {, outlet }}}-1\right)_{\text {cloth only }}=\frac{\nu_{\text {cloth,only }} A_{\text {cloth,only }}}{V}
$$

Reactivity-Influencing Factors. Dominance analysis is designed to determine the relative importance of one variable over another in a given data set. ${ }^{48,49}$ It measures the relative importance in all possible subset models in a pairwise manner (in total $2^{n}-1$ models, $n$ : number of variables), i.e., all pairs of variables are compared. ${ }^{50}$ The dominance of one variable over another is calculated by comparing their incremental $R^{2}$ contributions over the complete data set. ${ }^{48,49}$ In this study, dominance analysis (in Python) was applied to determine the relative importance of a set of target variables discussed in the manuscript for the total $\mathrm{OH}$ reactivity and the $\mathrm{OH}$ reactivity of some important reactive VOCs associated with dermal emissions. Specifically, the following target variables were tested: indoor $\mathrm{O}_{3}$ concentration, indoor air temperature and relative humidity, clothing, age, and volunteer group (six variables). Ozone, temperature, $\mathrm{RH}$, and clothing factors are discussed in this manuscript, while age and volunteer groups were discussed in Wang et al. ${ }^{34}$ The clothing factor was used to distinguish between volunteers wearing long clothing or short clothing. As the age factor, the average age of the volunteers occupying the chamber was used. The volunteer group factor was used to distinguish between the five different groups of subjects occupying the chamber during the ICHEAR experiments. Steady-state values of $\mathrm{OH}$ reactivity, $\mathrm{O}_{3}$, temperature, and $\mathrm{RH}$ data were used in these analyses. The data set comprised all experiments performed during the ICHEAR campaign on whole body emissions. For long experimental days, both morning and afternoon steady-state values were used separately in the analyses $(n=33) .^{33}$

\section{RESULTS AND DISCUSSION}

Ozone and Clothing Effect. Experiments (6), (7), (8), (9) and their respective replicates (21), (22), (23), (24) (Table S1), all conducted with volunteer group A2, probed differences in $\mathrm{OH}$ reactivity from occupant emissions under different clothing conditions. During these experiments, the chamber air temperature was moderate (set point $25^{\circ} \mathrm{C}$ ) and its relative humidity low (set point $25 \%$ ). Figure 1 shows the measured total $\mathrm{OH}$ reactivity (filled bars) and the summed calculated $\mathrm{OH}$ reactivity (empty bars) averaged over the final $15 \mathrm{~min}$ of each experiment (emissions at steady state ${ }^{33}$ ) for each condition: long clothing before $\mathrm{O}_{3}$ addition $(6$ and 21 morning); long clothing with $\mathrm{O}_{3}$ added after emissions reached 
SS (6 and 21 afternoon); long clothing with $\mathrm{O}_{3}$ present from the start of the experiment ( 7 and 22); short clothing before $\mathrm{O}_{3}$ addition ( 8 and 23 morning); short clothing with $\mathrm{O}_{3}$ added after emissions reached SS (8 and 23 afternoon); and short clothing with $\mathrm{O}_{3}$ present from the start of the experiment (9 and 24).

With $\mathrm{O}_{3}$ present, the measured total $\mathrm{OH}$ reactivity for the same group of volunteers ranged between $25 \pm 2$ and $35 \pm 0.2$ $\mathrm{s}^{-1}$ (mean value across replicates \pm 1 standard deviation). In the absence of $\mathrm{O}_{3}$, the $\mathrm{OH}$ reactivity was smaller $(8 \pm 3$ to 11 $\pm 7 \mathrm{~s}^{-1}$ for short and long clothing) consistent with the experiments examined in Wang et al. ${ }^{34}$ Differences in $\mathrm{OH}$ reactivity for $\mathrm{O}_{3}$-free conditions are attributed primarily to variability in isoprene $\left(\mathrm{C}_{5} \mathrm{H}_{8}\right)$ emission rates ${ }^{33}$ (differences in measured $\mathrm{OH}$ reactivity up to $24 \%$ and in calculated $\mathrm{OH}$ reactivity up to $22 \%$ ). In the presence of $\mathrm{O}_{3}$, the measured $\mathrm{OH}$ reactivity between replicates agree within 1-18\%. A similar agreement was observed for the respective calculated values (agreement within 1-18\%, uncertainty on measurements $\sim 48 \%$, uncertainty of calculations $\sim 30 \%$ ). The replicates suggest that small differences in VOC emissions were present within the same group of volunteers on different experimental days.

For both clothing conditions, an increasing trend of $\mathrm{OH}$ reactivity was observed when $\mathrm{O}_{3}$ was introduced after steadystate conditions had been reached $\left(29 \pm 5\right.$ and $35 \pm 0.2 \mathrm{~s}^{-1}$, mean measured $\mathrm{OH}$ reactivity for long and short clothing and standard deviation among replicates, respectively), compared to when $\mathrm{O}_{3}$ was introduced from the start of the experiment $\left(25 \pm 1.5\right.$ and $31 \pm 2.4 \mathrm{~s}^{-1}$, mean measured $\mathrm{OH}$ reactivity for long and short clothing, respectively); see Figure 1. Differences were statistically significant ( $p<0.05$, paired sample $t$-test) when occupants wore short clothing. With $\mathrm{O}_{3}$ present, the $\mathrm{OH}$ reactivity was significantly larger with short clothing compared to the condition when long clothing was worn $(p<0.05$, paired sample $t$-test).

As shown in Figure 1, differences between the measured total $\mathrm{OH}$ reactivity and the summed $\mathrm{OH}$ reactivity from the individually measured compounds are not significant, meaning that for the investigated conditions the reactive VOC budget, within the margin of uncertainty, is closed. Figure S1 examines the $\mathrm{OH}$ reactivity per chemical compound class, divided into hydrocarbons, alcohols, carboxylic acids, aromatic oxygenated compounds, carbonyl compounds, other oxygenated compounds, nitrogen-containing compounds, and sulfur-containing compounds (Table S2). In the absence of $\mathrm{O}_{3}$, when occupants wore long clothing, hydrocarbons (mainly represented by isoprene) explained $79 \%$ of the total $\mathrm{OH}$ reactivity, followed by carbonyls (15.7\%, mainly formaldehyde, acetaldehyde, 1,4butanedial, 6-MHO, 4-OPA, and geranyl acetone), other oxygenated compounds (1.45\%), aromatics (1\%), alcohols (1\%), sulfur-containing compounds $(0.8 \%)$, carboxylic acids $(0.7 \%)$, and nitrogen-containing compounds (0.4\%). Small differences were reported in the absence of $\mathrm{O}_{3}$, when occupants wore short clothing (hydrocarbons, carbonyls, and nitrogen-containing compounds explained $76 \%, 17 \%$, and $1.2 \%$ of the $\mathrm{OH}$ reactivity, respectively). In the presence of $\mathrm{O}_{3}$, and with occupants wearing long clothing, their $\mathrm{OH}$ reactivity was explained by carbonyls (59\%), hydrocarbons (34\%), others $(2.8 \%)$, aromatics $(1.7 \%)$, carboxylic acids (1\%), sulfurcontaining compounds $(0.5 \%)$, alcohols $(0.4 \%)$, and nitrogen-containing compounds $(0.3 \%)$. When occupants were wearing short clothing, carbonyls explained $65 \%$ of the total
OH reactivity, followed by hydrocarbons (27.4\%), others (2.9\%), aromatics (2\%), carboxylic acids (1.2\%), sulfurcontaining compounds $(0.8 \%)$, nitrogen-containing compounds $(0.3 \%)$, and alcohols $(0.3 \%)$.

In terms of specific species, when long clothing was worn and $\mathrm{O}_{3}$ was present from the start of experiments, the compounds most influencing the reactivity were 6-MHO $\left(\mathrm{C}_{8} \mathrm{H}_{14} \mathrm{O}, 9.4 \pm 2.2 \mathrm{~s}^{-1}\right)$ and isoprene $\left(\mathrm{C}_{5} \mathrm{H}_{8}, 9.3 \pm 1.3 \mathrm{~s}^{-1}\right)$, followed by 4-OPA $\left(\mathrm{C}_{5} \mathrm{H}_{8} \mathrm{O}_{2}, 1.8 \pm 0.4 \mathrm{~s}^{-1}\right)$, 1,4-butanedial $\left(\mathrm{C}_{4} \mathrm{H}_{6} \mathrm{O}_{2}, 1.4 \pm 0.3 \mathrm{~s}^{-1}\right)$, and acetaldehyde $\left(\mathrm{C}_{2} \mathrm{H}_{4} \mathrm{O}, 1.4 \pm 0.2\right.$ $\left.\mathrm{s}^{-1}\right)$; values in parentheses correspond to the $\mathrm{OH}$ reactivity \pm 1 standard deviation reported for the experimental replicates of the same condition (Table S3). In comparison, when $\mathrm{O}_{3}$ was added after the gas-phase concentration of occupant emitted compounds reached steady state (afternoon), compounds related to dermal emissions such as geranyl acetone $(0.50 \pm$ $\left.0.06 \mathrm{~s}^{-1}\right)$ and 6-MHO $\left(9.91 \pm 0.02 \mathrm{~s}^{-1}\right)$ had a larger $\mathrm{OH}$ reactivity. Carbonyls had an even larger influence on the $\mathrm{OH}$ reactivity for occupants wearing short clothing: 6-MHO (14 \pm $\left.0.6 \mathrm{~s}^{-1}\right)$ and isoprene $\left(10.2 \pm 0.8 \mathrm{~s}^{-1}\right)$, followed by 4-OPA $(3.2$ $\left.\pm 0.1 \mathrm{~s}^{-1}\right)$, 1,4-butanedial $\left(2 \pm 0.03 \mathrm{~s}^{-1}\right)$, and acetaldehyde $\left(1.6 \pm 0.03 \mathrm{~s}^{-1}\right)$. In the case of occupants wearing short clothing when $\mathrm{O}_{3}$ was added in the afternoon, the $\mathrm{OH}$ reactivity of some carbonyl compounds, including 6-MHO $\left(15.3 \pm 0.4 \mathrm{~s}^{-1}\right)$ and geranyl acetone $\left(1 \pm 0.1 \mathrm{~s}^{-1}\right)$ further increased. Figure 2 shows the time series of 6-MHO, 4-OPA, and geranyl acetone concentrations. A 35-51\% increase in the concentrations of those three compounds is associated with occupants wearing short rather than long clothing. In the

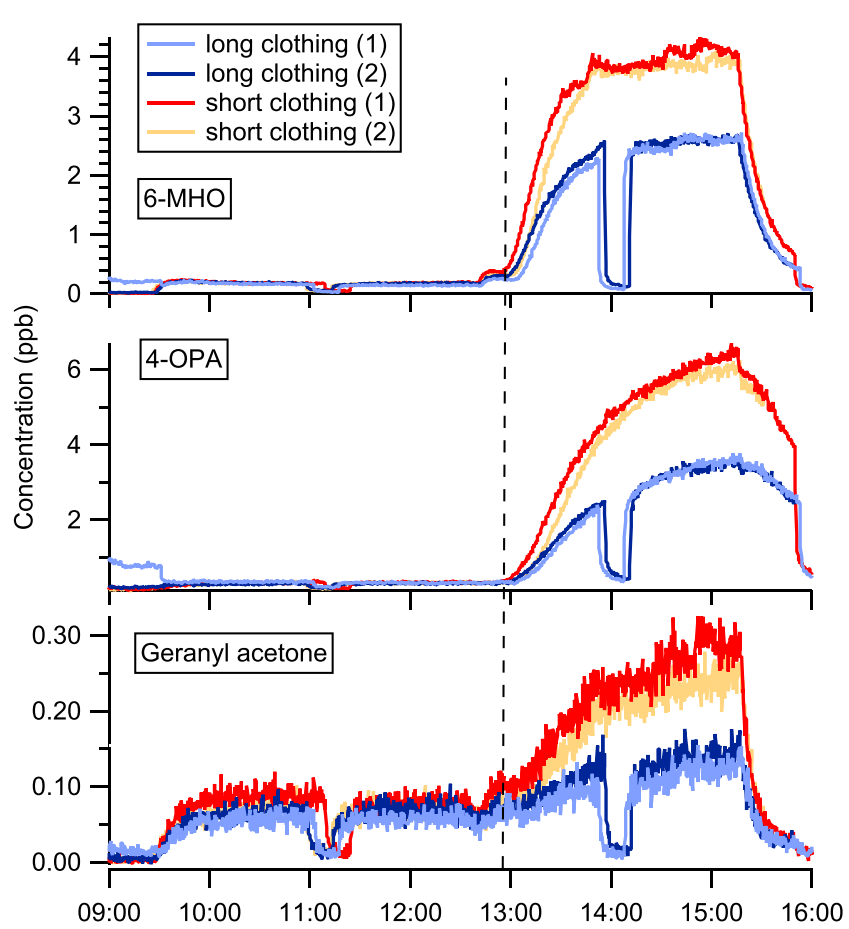

Figure 2. Concentrations of 6-MHO, 4-OPA, and geranyl acetone measured in the chamber occupied from 9:30 by four adults wearing long/short clothing. For each condition, two replicate experiments $(N$ = 2) were conducted (long clothing conditions (6), (21), short clothing conditions (8), (23); see Table S1). The dashed line indicates when ozone was mixed into the chamber air. The dips correspond to measurements of the chamber supply air. 
presence of $\mathrm{O}_{3}$, clothing coverage of bare skin significantly influences the $\mathrm{OH}$ reactivity.

Depending on the clothing worn and the timing of the $\mathrm{O}_{3}$ introduction to the chamber, four cases can be distinguished: (i) clean long clothing worn just prior to $\mathrm{O}_{3}$ exposure $\left(\mathrm{O}_{3}\right.$ from start), (ii) long clothing worn for $\sim 3 \mathrm{~h}$ prior to $\mathrm{O}_{3}$ exposure $\left(\mathrm{O}_{3}\right.$ from $\mathrm{SS}$ ), (iii) clean short clothing worn just prior to $\mathrm{O}_{3}$ exposure $\left(\mathrm{O}_{3}\right.$ from start), and (iv) short clothing worn for $\sim 3 \mathrm{~h}$ prior to $\mathrm{O}_{3}$ exposure ( $\mathrm{O}_{3}$ from SS). The $\mathrm{O}_{3}$ deposition velocity on the occupants $\left(\nu_{\text {occ }}\right)$ was calculated for each of these cases to investigate whether the observed $\mathrm{OH}$ reactivity and VOC mixing ratios are compatible with bare skin-surface-to-clothed-surface area, and how clothing cleanliness influences emission (Table S4). Ozone deposition velocities calculated in our experiments are close to the upper limits of values previously reported in the literature ${ }^{8,20}$ for similar conditions. This is due to possibly higher air mixing achieved by the fans in the chamber. When $\mathrm{O}_{3}$ was added in the chamber from steady state in the afternoon (and occupants had been wearing the clothes for a longer time), $\mathrm{O}_{3}$ deposition velocity showed a small increase, while a larger increase and consistent trend was reported for $\mathrm{k}_{\mathrm{occ}}$, VOC concentrations, and $\mathrm{OH}$ reactivity (Table $\mathrm{S} 4$ ). The yield was presumably enhanced by the presence of skin flakes or skin oil deposited on the clean clothing during the day, in agreement with the results reported by Lakey et al. ${ }^{51}$

In comparison, the $\mathrm{O}_{3}$ deposition velocity of four clean $\mathrm{t}$ shirts $(6.9 \mathrm{~m} / \mathrm{h})$ and four soiled t-shirts $(9.4 \mathrm{~m} / \mathrm{h})$, exposed to $\mathrm{O}_{3}$ in the chamber are reported in Table S5. Results are in agreement with values reported in the literature ${ }^{18,19,52}$ but are substantially lower than those measured for the clothed occupants in this study. We observed very little difference in $\mathrm{O}_{3}$ removal for occupants wearing long or short clothing; therefore, the deposition velocity of clothing that is being worn is nearly the same as that of skin but higher than that of the clothing that was tested on its own. It is possible that the deposition velocity for clothing worn by people is higher because of enhanced convection around a body. The measured total $\mathrm{OH}$ reactivity of clean clothing was below the limit of detection $\left(5 \mathrm{~s}^{-1}\right)$ and of soiled clothing was $7 \pm 3 \mathrm{~s}^{-1}$. The total $\mathrm{OH}$ reactivity of clothing and occupants depends on concentrations of the most reactive compounds generated from $\mathrm{O}_{3}$-initiated chemistry with skin oil. This chemistry depends on the $\mathrm{O}_{3}$ concentration inside the chamber and the mass-transport limited $\mathrm{O}_{3}$ flux to surfaces. Taking this into account, the $\mathrm{OH}$ reactivity is expected to scale with $\mathrm{O}_{3}$ concentration in an occupied, or recently occupied indoor environment.

Effect of Temperature and Humidity. To assess the effect of temperature and humidity, conditions (1), (4), and $(2)^{33}$ (Table S1) are examined in Figure 3, for the measured total $\mathrm{OH}$ reactivity, summed calculated $\mathrm{OH}$ reactivity, 6$\mathrm{MHO}, 4-\mathrm{OPA}$, and geranyl acetone $\mathrm{OH}$ reactivities. Specifically, four adult volunteers (group A1) occupied the chamber, wearing long clothing, at moderate air temperature (set point $25{ }^{\circ} \mathrm{C}$ ) and low $\mathrm{RH}$ (set point $25 \%$ ), at high temperature (set point $31{ }^{\circ} \mathrm{C}$ ) and low $\mathrm{RH}$, and at high temperature and $\mathrm{RH}$ (set point 65\%); the actual temperatures were higher than the set points (see Table $\mathrm{S} 1$ ). In all cases, $\mathrm{O}_{3}$ was added to the chamber air after the occupant VOC emissions reached steadystate condition. Similar to the case of clothing, $\mathrm{OH}$ reactivity increased when $\mathrm{O}_{3}$ was present due to the presence of reactive carbonyls generated from skin ozonolysis reactions. With $\mathrm{O}_{3}$

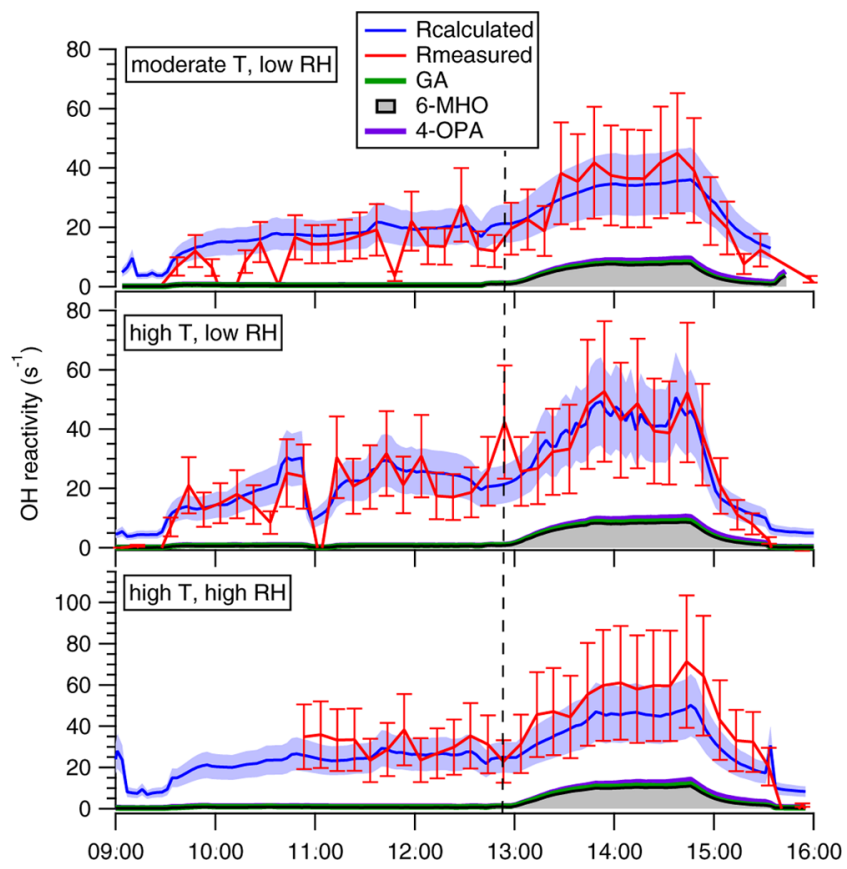

Figure 3. Measured and calculated $\mathrm{OH}$ reactivity from four adults occupying the chamber from 9:30, wearing long clothing, exposed to moderate or high temperature $(T)$, and low or high humidity $(\mathrm{RH})$. Ozone was added to the chamber air when occupant emissions reached steady state (dashed vertical line). Total measured and calculated $\mathrm{OH}$ reactivities are reported with their associated method uncertainties, 48 and 30\%, respectively. 6-MHO, 4-OPA, and geranyl acetone (GA) $\mathrm{OH}$ reactivities are reported with the gray area and colored lines, respectively. Missing data points for the first $1.5 \mathrm{~h}$ in the bottom panel are due to instrument failure. The dip in the experiment at a high $T$ and a low $\mathrm{RH}$ corresponds to the measurement of the chamber supply air.

present, the total $\mathrm{OH}$ reactivity measured at steady state (15 min before end of the exposure) varied between $41 \mathrm{~s}^{-1}$ (moderate temperature, low $\mathrm{RH}$ ) and $63 \mathrm{~s}^{-1}$ (high temperature, high $\mathrm{RH}$ ). For each positive change in condition (increased air temperature, increased relative humidity), higher concentrations of reactive compounds were present. In all three cases, the reactive VOC budget was closed within the margin of uncertainty (Figure 3 ).

The classes of chemical compounds contributing to the total $\mathrm{OH}$ reactivity and their mixing ratios are shown in Figure 4. At a moderate temperature and a low $\mathrm{RH}$, the dominant reactive compounds were carbonyls (51\%), followed by hydrocarbons $(41 \%)$, others $(2.3 \%)$, aromatics $(1.5 \%)$, nitrogen-containing compounds $(1.4 \%, 96 \%$ of this fraction is represented by $\mathrm{NH}_{3}$ ), carboxylic acids (1\%), sulfur compounds (0.6\%), and alcohols $(0.5 \%)$. In contrast to the $\mathrm{OH}$ reactivity, the total mixing ratio of the chemical compounds, which depends only on the abundance of the measured chemicals, is dominated by nitrogen-containing compounds, specifically by ammonia $\left(\mathrm{NH}_{3}, 58 \%\right)$, carbonyl compounds (30\%), alcohols $(3.8 \%)$, carboxylic acids $(3.4 \%)$, hydrocarbons $(3.2 \%)$, others $(0.5 \%)$, aromatics $(0.3 \%)$, and sulfur compounds $(0.2 \%)$. The reader should note that $\mathrm{NH}_{3}$ measurements were not available during the experiments involving group $\mathrm{A} 2\left(\mathrm{O}_{3}\right.$ and clothing effect). Results reported in Figure S1 (group A1) and Figure 4 (group A2) are in agreement, within the variability between groups observed in Wang et al. ${ }^{34}$ 

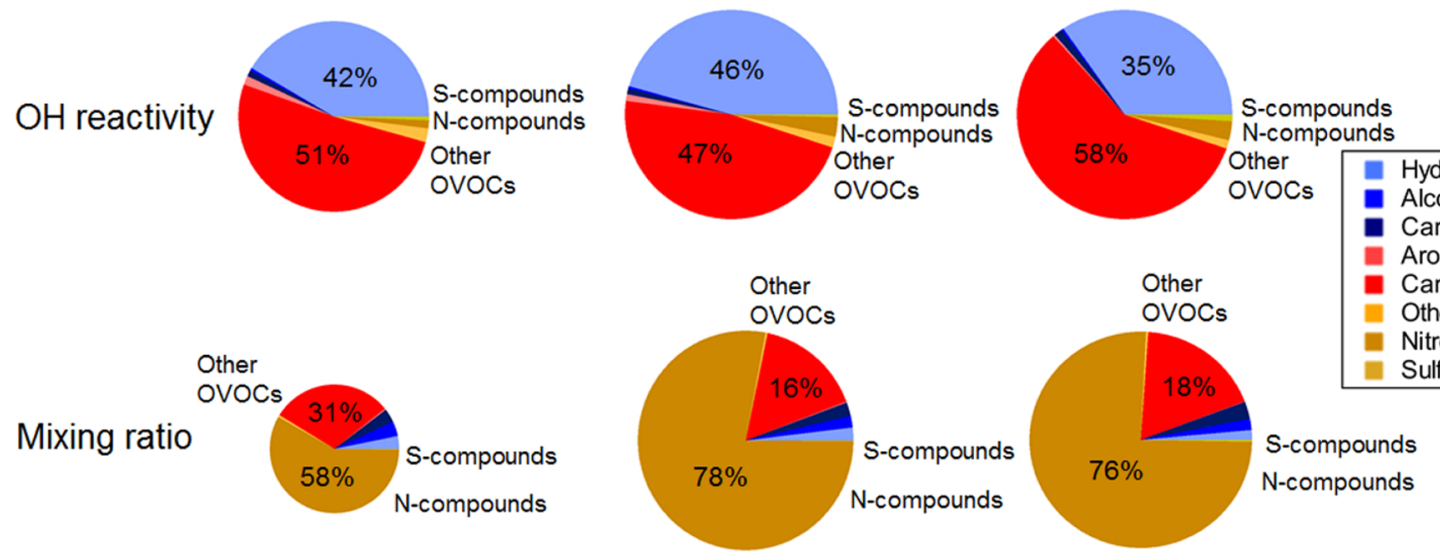

Hydrocarbons
- Alcohols
- Arboxylic acids
Aromatic OVOCs

Carbonyl OVOCs

Other OVOCs

Nitrogen containing compounds Sulfur containing compounds

\section{$\mathrm{T}=$ moderate $\mathrm{RH}=$ low}

$\mathrm{T}=$ high $\mathrm{RH}=$ low

T=high $\mathrm{RH}=$ high

Figure 4. Speciated total $\mathrm{OH}$ reactivity (top row) and speciated total mixing ratios (bottom row) measured at the steady state with $\mathrm{O}_{3}$ present; four adults wearing long clothing occupied the climate chamber at various temperatures $(T)$ and relative humidities $(\mathrm{RH})$. Total OH reactivities represented in the pie charts in the top row are $32 \pm 10,41 \pm 12$, and $40 \pm 12 \mathrm{~s}^{-1}$, for the three cases, moderate $T$ and low RH, high $T$ and low $\mathrm{RH}$, and high $T$ and high $\mathrm{RH}$, respectively. Total mixing ratios represented in the pie charts in the bottom row are $190 \pm 13,405 \pm 33$, and $393 \pm$ $32 \mathrm{ppb}$, for the three cases, moderate $T$ and low RH, high $T$ and low RH, and high $T$ and high $\mathrm{RH}$, respectively. The size of the pie charts is scaled to the total values, different scales are used between pies representing $\mathrm{OH}$ reactivity and pies representing the mixing ratios. Steady-state values were determined during the last $15 \mathrm{~min}$ before occupants left the chamber.

A small increase in temperature (at low $\mathrm{RH}$ ), leaves the speciation of $\mathrm{OH}$ reactivity almost unchanged relative to the base case (the total hydrocarbon and carbonyl fractions $\mathrm{OH}$ reactivities increase, respectively, by 5.5 and $3 \mathrm{~s}^{-1}$ ). In contrast, the fractional mixing ratio is remarkably different, with the fraction of nitrogen-containing compounds (primarily $\mathrm{NH}_{3}$ ) increasing to $78 \%$. The temperature-dependent emissions of ammonia were reported by $\mathrm{Li}$ et al. ${ }^{43}$ for the same experiments. The fractional contribution of other groups of compounds to the total mixing ratio decreased with increasing temperature (Figure 4). However, an increase in concentration was seen for geranyl acetone, a primary product of squalene ozonolysis, and 6-MHO, which is both a primary and secondary product of the reaction between squalene and $\mathrm{O}_{3}$ (Figure S2). Given the relatively small changes in absolute temperature in the chamber, changes in the gas-phase rate coefficients are anticipated to be small. Higher temperatures will increase the volatility of compounds from all surfaces in the chamber. However, human skin surface temperature changes are modulated metabolically. Increased sweat production will increase water vapor at the skin surface, favoring production of carbonyls over less volatile secondary ozonides. ${ }^{24}$ Further, sweat may alter the metabolic activity of the skin microbiome, resulting in a different suite of microbial emissions. At a high temperature and a high $\mathrm{RH}$, carbonyl compounds dominated the total $\mathrm{OH}$ reactivity (58\%), followed by hydrocarbons (35\%), nitrogen-containing compounds (3\%, of which $98 \%$ is $\mathrm{NH}_{3}$ ), others (1.3\%), carboxylic acids (1.2\%), S-compounds (1\%), alcohols $(0.4 \%)$, and aromatics $(0.3 \%)$. The total concentration instead, was dominated by $\mathrm{NH}_{3}$ (75\%, $99.5 \%$ of the total concentration of nitrogen-containing compounds), carbonyls $(+3 \%$ compared to low $\mathrm{RH})$, and carboxylic acids $(+0.6 \%)$. With respect to the base case (moderate temperature, low $\mathrm{RH}$ ), the steady-state 6-MHO concentration increased by $9 \%$ with the increase in temperature and by $27 \%$ with the increase in temperature and $\mathrm{RH}$. Geranyl acetone concentration increased by $27 \%$ with the increase in temperature and $54 \%$ with the increase in temperature and $\mathrm{RH}$. The 4-OPA concentration did not increase significantly $(<1 \%)$ when temperature increased, while it increased by $34 \%$ when temperature and $\mathrm{RH}$ increased (Figure S2). The results from this study are in agreement with the study from Arata et al. ${ }^{24}$ for heterogeneous ozonolysis of squalene in a flow tube and skin oils on soiled t-shirts in the same climate chamber, where higher RH caused a greater yield of carbonyls from the Criegee intermediates of the squalene- $\mathrm{O}_{3}$ reaction.

$\mathrm{OH}$ Reactivity-Influencing Factors. A dominance analysis was conducted to investigate the relative importance of the factors discussed in this study (indoor $\mathrm{O}_{3}$ concentration, clothing, temperature, and humidity) and in Wang et al. (age and group variability), ${ }^{34}$ for the total $\mathrm{OH}$ reactivity and individual $\mathrm{OH}$ reactivities of geranyl acetone, 6-MHO, and 4OPA. The analysis aims at identifying the main drivers of human $\mathrm{OH}$ reactivity indoors through the relative importance of the target variables (see the Methods section). The $\mathrm{OH}$ reactivity data set comprises experiments conducted on whole body emissions of four volunteers occupying the chamber. ${ }^{33}$ The target factors varied in the following experimental ranges: indoor $\mathrm{O}_{3}$ concentration: $0-44.2 \mathrm{ppb}$; air temperature: $26-$ $32.8{ }^{\circ} \mathrm{C}$, air humidity: $18-63 \%$, clothing coverage: short/long; age group: teenager/adult/senior; and five different groups of volunteers: $\mathrm{A} 1, \mathrm{~A} 2, \mathrm{~A} 3, \mathrm{~T} 4, \mathrm{~S} 5 .{ }^{33}$

The dominance analysis of total $\mathrm{OH}$ reactivity (Figure S3) shows that $\mathrm{O}_{3}$ has the largest impact on the total $\mathrm{OH}$ reactivity $(85 \%)$, followed by clothing (6\%), variability between the groups of subjects occupying the chamber (group factor), temperature and humidity having comparable impact (2.5$3 \%$, while the age of volunteers has a negligible impact in comparison. Ozone initiates surface reactions with skin lipids generating reactive VOCs whose $\mathrm{OH}$ reactivity is represented under the total $\mathrm{OH}$ reactivity term. When the same analysis is conducted without $\mathrm{O}_{3}$ as a target variable, the ranking of the other factors is preserved. The skin-related compounds, namely, geranyl acetone, 6-MHO, and 4-OPA, have $\mathrm{OH}$ reactivities influenced mostly by the factors $\mathrm{O}_{3}$ and clothing. 6$\mathrm{MHO}$, which is both a primary and secondary product of 
squalene ozonolysis, and 4-OPA, a secondary product only, are considerably more influenced by $\mathrm{O}_{3}$ than geranyl acetone, a primary product of squalene ozonolysis. Among clothing, temperature, and humidity, the analysis finds that clothing is the most important factor. In our experiments, the clothing effect was examined with group A2, while temperature and humidity were examined with group $\mathrm{A} 1$. Total $\mathrm{OH}$ reactivity of group $\mathrm{A} 1$ emissions was higher than the total $\mathrm{OH}$ reactivity of group A2 emissions, masking the relative importance of the clothing factor compared to humidity and temperature. The squalene reduction observed from the skin wipes sampled before and after each experiment from the individuals in groups $\mathrm{A} 1$ and $\mathrm{A} 2$ is in general agreement with the total $\mathrm{OH}$ reactivity. That is, a larger reduction in squalene is observed for the higher reactivity (up to $77 \%$ reduction of squalene for up to $63 \mathrm{~s}^{-1} \mathrm{OH}$ reactivity), and a larger reduction is observed in A1 ( $68 \%$ on average) than A2 ( $20 \%$ on average).

These results highlight the importance of skin emissions and their ozonolysis products for the $\mathrm{OH}$ reactivity of human occupants indoors, their variability with temperature, relative humidity, and clothing, and ultimately their importance for indoor air quality.

Outdoor to indoor transport of $\mathrm{O}_{3}$ and exposed skin surface area are especially important factors. On a hot summer day spent indoors in a city with high concentrations of ground-level $\mathrm{O}_{3}$, more ventilation (increasing indoor $\mathrm{O}_{3}$ ), or less clothing (increasing $\mathrm{O}_{3}$ flux to bare skin) may be necessary to improve comfort. If more people occupy the same indoor environment, the effect on indoor air chemistry will be further amplified. 4OPA and 6-MHO are known respiratory irritants, ${ }^{53,54}$ while the concomitant effect of exposure to multiple chemicals and the risk to certain population sectors is yet unknown. ${ }^{55}$ Remarkably, the indoor $\mathrm{OH}$ reactivity measured here for the first time was comparable to the $\mathrm{OH}$ reactivity measured in a variety of outdoor environments, including cities ${ }^{56-58}$ and forests. $^{58,59}$

Current Results in Relation to the Findings from Wang et al. and Previous Studies. Results reported in Wang et $\mathrm{al}^{34}$ comprised experiments (1), (6), (21), (10), (18), (26), (16), (25), (12), and (13); results from the current study comprise experiments (1), (2), (4), (6), (7), (8), (9), (21), (22), (23), and (24). ${ }^{33}$ Recall that Wang et al. ${ }^{34}$ analyzed the $\mathrm{OH}$ reactivity of isolated breath and dermal emissions as well as whole-body emissions from volunteers of different age groups in the presence and absence of ozone and found that the $\mathrm{OH}$ reactivity could be accounted for by the trace gases measured and that it was sensitive to ozone but not to age. The current study focuses on the impact of varied environmental factors on two groups of adult volunteers, as well as reproducibility for sets of duplicated experiments. Results from these experiments have not been previously reported and are particularly relevant to the dependency of human $\mathrm{OH}$ reactivity on the absence or presence of $\mathrm{O}_{3}$, and the change in the $\mathrm{OH}$ reactivity of human emissions with changes in skin coverage by clothing, air temperature, and relative humidity. Skin coverage by clothing and worn/soiled clothing play an important role in the ozonolysis of skin-oil constituents. The role of clothing has been previously investigated in a number of $\mathrm{O}_{3}$ and VOCs experiments, ${ }^{18,21,52,60}$ modeling studies ${ }^{19,51}$ and now through measurements of occupant $\mathrm{OH}$ reactivity (this work). Additionally, to our knowledge, this is the first study reporting the effect of temperature on occupant VOC emissions and their $\mathrm{OH}$ reactivity. The experimental reproducibility of $\mathrm{OH}$ reactivity measurements across replicated experiments $(6-21,7-22,8-23$, and 9-24) reported in this work demonstrates that this technique can be used with confidence in indoor air studies. With $\mathrm{O}_{3}$ present, the standard deviation among steady-state values was $<18 \%$, and the method uncertainty was $\sim 48 \%$. With $\mathrm{O}_{3}$ absent, the mean measured $\mathrm{OH}$ reactivity was $10 \pm 2 \mathrm{~s}^{-1}$ and the standard deviation among the steady-state reactivity values was $24 \%$, which is mainly explained by the increased uncertainty of the method for measuring $\mathrm{OH}$ reactivity when values are close to the instrumental limit of detection. ${ }^{42}$

\section{ASSOCIATED CONTENT}

\section{SI Supporting Information}

The Supporting Information is available free of charge at https://pubs.acs.org/doi/10.1021/acs.est.1c01831.

Experimental conditions included in this study (Table S1); volatile organic compounds and their classification in compounds classes used to determine the summed calculated $\mathrm{OH}$ reactivity (Table S2); speciated $\mathrm{OH}$ reactivity from occupants wearing long clothing and short clothing, before ozone exposure, with ozone added at the steady state of emissions (afternoon), and with ozone added from the beginning of the experiment (Figure S1); 10 most reactive volatile organic compounds emitted by four adult volunteers wearing long clothing and short clothing exposed to ozone from start of the experiment and in the afternoon, from SS of the emissions (Table S3); calculated $\mathrm{O}_{3}$ deposition velocity on four occupants $\left(v_{\text {occ }}\right)$, first-order rate constant for $\mathrm{O}_{3}$ loss $\left(k_{\mathrm{d}}\right)$, measured 6-MHO, 4-OPA, geranyl acetone concentrations, and measured total $\mathrm{OH}$ reactivity at SS for each experimental condition (Table S4); ozone deposition velocity and $\mathrm{OH}$ reactivity of four clean and soiled (worn overnight $\sim 8 \mathrm{~h}$ ) t-shirts, and corresponding parameters used (Table S5); 10 most reactive volatile organic compounds emitted by four adult volunteers wearing long clothing exposed to ozone, at moderate temperature and low $\mathrm{RH}$, high temperature and low $\mathrm{RH}$, and high temperature and high $\mathrm{RH}$ (Table S6); concentrations of 6-MHO, 4-OPA, and geranyl acetone measured in the chamber occupied by four adults from 9:30, wearing long clothing, and exposed to low/high temperature and low/high relative humidity (Figure S2); dominance analysis for the total $\mathrm{OH}$ reactivity of human beings, with varying conditions of ozone exposure, short/long clothing, volunteers groups, relative humidity, temperature, and age of volunteers (teens/adults/ seniors) (Figure S3) (PDF)

\section{AUTHOR INFORMATION}

\section{Corresponding Author}

Nora Zannoni - Atmospheric Chemistry Department, Max Planck Institute for Chemistry, 55128 Mainz, Germany; ○ orcid.org/0000-0003-2721-5362; Email: nora.zannoni@ mpic.de

\section{Authors}

Mengze Li - Atmospheric Chemistry Department, Max Planck Institute for Chemistry, 55128 Mainz, Germany; 다 orcid.org/0000-0003-0620-6301 
Nijing Wang - Atmospheric Chemistry Department, Max Planck Institute for Chemistry, 55128 Mainz, Germany; (1) orcid.org/0000-0003-3197-8151

Lisa Ernle - Atmospheric Chemistry Department, Max Planck Institute for Chemistry, 55128 Mainz, Germany

Gabriel Bekö - International Centre for Indoor Environment and Energy, Department of Civil Engineering, Technical University of Denmark, 2800 Lyngby, Denmark; (1) orcid.org/0000-0001-6107-8336

Pawel Wargocki - International Centre for Indoor Environment and Energy, Department of Civil Engineering, Technical University of Denmark, 2800 Lyngby, Denmark Sarka Langer - IVL Swedish Environmental Research Institute, 41133 Göteborg, Sweden; Division of Building Services Engineering, Department of Architecture and Civil Engineering, Chalmers University of Technology, 41296 Göteborg, Sweden; (1) orcid.org/0000-0002-6580-8911

Charles J. Weschler - International Centre for Indoor Environment and Energy, Department of Civil Engineering, Technical University of Denmark, 2800 Lyngby, Denmark; Environmental and Occupational Health Sciences Institute, Rutgers University, Piscataway, New Jersey 08854, United States; orcid.org/0000-0002-9097-5850

Glenn Morrison - Department of Environmental Sciences and Engineering, Gillings School of Global Public Health, The University of North Carolina at Chapel Hill, Chapel Hill, North Carolina 27599-7431, United States; 이이.org/ 0000-0001-6876-7185

Jonathan Williams - Atmospheric Chemistry Department, Max Planck Institute for Chemistry, 55128 Mainz, Germany; 이이.org/0000-0001-9421-1703

Complete contact information is available at: https://pubs.acs.org/10.1021/acs.est.1c01831

\section{Funding}

Open access funded by Max Planck Society.

\section{Notes}

The authors declare no competing financial interest.

\section{ACKNOWLEDGMENTS}

This study was funded by the Alfred P. Sloan Foundation (Grant no. G-2018-11233). Nico Ziersen, Thomas Klüpfel, and Rolf Hofmann are acknowledged for their support. The authors are thankful to the volunteers for participating in the study.

\section{REFERENCES}

(1) Klepeis, N. E.; Nelson, W. C.; Ott, W. R.; Robinson, J. P.; Tsang, A. M.; Switzer, P.; Behar, J. V.; Hern, S. C.; Engelmann, W. H. The National Human Activity Pattern Survey (NHAPS): A Resource for Assessing Exposure to Environmental Pollutants. J. Exposure Sci. Environ. Epidemiol. 2001, 11, 231-252.

(2) Press Corner: https://ec.europa.eu/commission/presscorner/ home/en (accessed Jan 24, 2021).

(3) US EPA, O. Introduction to Indoor Air Quality https://www. epa.gov/indoor-air-quality-iaq/introduction-indoor-air-quality (accessed Jan 24, 2021).

(4) Ault, A. P.; Grassian, V. H.; Carslaw, N.; Collins, D. B.; Destaillats, H.; Donaldson, D. J.; Farmer, D. K.; Jimenez, J. L.; McNeill, V. F.; Morrison, G. C.; O’Brien, R. E.; Shiraiwa, M.; Vance, M. E.; Wells, J. R.; Xiong, W. Indoor Surface Chemistry: Developing a Molecular Picture of Reactions on Indoor Interfaces. Chem 2020, 6, 3203-3218.
(5) Tang, X.; Misztal, P. K.; Nazaroff, W. W.; Goldstein, A. H. Volatile Organic Compound Emissions from Humans Indoors. Environ. Sci. Technol. 2016, 50, 12686-12694.

(6) Weschler, C. J. Roles of the Human Occupant in Indoor Chemistry. Indoor Air 2016, 26, 6-24.

(7) de Lacy Costello, B.; Amann, A.; Al-Kateb, H.; Flynn, C.; Filipiak, W.; Khalid, T.; Osborne, D.; Ratcliffe, N. M. A Review of the Volatiles from the Healthy Human Body. J. Breath Res. 2014, 8, No. 014001.

(8) Wisthaler, A.; Weschler, C. J. Reactions of Ozone with Human Skin Lipids: Sources of Carbonyls, Dicarbonyls, and Hydroxycarbonyls in Indoor Air. Proc. Natl. Acad. Sci. USA 2010, 107, 6568-6575.

(9) Lakey, P. S. J.; Wisthaler, A.; Berkemeier, T.; Mikoviny, T.; Pöschl, U.; Shiraiwa, M. Chemical Kinetics of Multiphase Reactions between Ozone and Human Skin Lipids: Implications for Indoor Air Quality and Health Effects. Indoor Air 2017, 27, 816-828.

(10) Kruza, M.; Carslaw, N. How Do Breath and Skin Emissions Impact Indoor Air Chemistry? Indoor Air 2019, 29, 369-379.

(11) Amann, A.; Costello, B.; Miekisch, W.; Schubert, J.; Buszewski, B.; Pleil, J.; Ratcliffe, N.; Risby, T. The Human Volatilome: Volatile Organic Compounds (VOCs) in Exhaled Breath, Skin Emanations, Urine, Feces and Saliva. J. Breath Res. 2014, 8, No. 034001.

(12) Furukawa, S.; Sekine, Y.; Kimura, K.; Umezawa, K.; Asai, S.; Miyachi, H. Simultaneous and Multi-Point Measurement of Ammonia Emanating from Human Skin Surface for the Estimation of Whole Body Dermal Emission Rate. J. Chromatogr. B 2017, 1053, 60-64.

(13) Weschler, C. J.; Carslaw, N. Indoor Chemistry. Environ. Sci. Technol. 2018, 52, 2419-2428.

(14) Grøntoft, T.; Raychaudhuri, M. R. Compilation of Tables of Surface Deposition Velocities for $\mathrm{O} 3, \mathrm{NO} 2$ and $\mathrm{SO} 2$ to a Range of Indoor Surfaces. Atmos. Environ. 2004, 38, 533-544.

(15) Morrison, G. C.; Nazaroff, W. W. The Rate of Ozone Uptake on Carpets: Experimental Studies. Environ. Sci. Technol. 2000, 34, 4963-4968.

(16) Gall, E.; Darling, E.; Siegel, J. A.; Morrison, G. C.; Corsi, R. L. Evaluation of Three Common Green Building Materials for Ozone Removal, and Primary and Secondary Emissions of Aldehydes. Atmos. Environ. 2013, 77, 910-918.

(17) Bako-Biro, Z.; Weschler, C. J.; Wargocki, P.; Fanger, P. O. Effects of Indoor Pollution Sources and Ventilation Rate on Ozone Surface Removal Rate and the Occurrence of Oxygenated VOCs in an Office Space. In 10th International Conference on Indoor Air Quality and Climate, 2005; pp 2320-2324.

(18) Tamás, G.; Weschler, C. J.; Bakó-Biró, Z.; Wyon, D. P.; StrømTejsen, P. Factors Affecting Ozone Removal Rates in a Simulated Aircraft Cabin Environment. Atmos. Environ. 2006, 40, 6122-6133.

(19) Rim, D.; Gall, E. T.; Ananth, S.; Won, Y. Ozone Reaction with Human Surfaces: Influences of Surface Reaction Probability and Indoor Air Flow Condition. Build. Environ. 2018, 130, 40-48.

(20) Pandrangi, L. S.; Morrison, G. C. Ozone Interactions with Human Hair: Ozone Uptake Rates and Product Formation. Atmos. Environ. 2008, 42, 5079-5089.

(21) Coleman, B. K.; Destaillats, H.; Hodgson, A. T.; Nazaroff, W. W. Ozone Consumption and Volatile Byproduct Formation from Surface Reactions with Aircraft Cabin Materials and Clothing Fabrics. Atmos. Environ. 2008, 42, 642-654.

(22) Nagda, N.; Nazaroff, W.; Gadgil, A.; Weschler, C. STP13101S Modeling of Indoor Air Quality and Exposure; ASTM International: West Conshohocken, PA, 1993.

(23) Yang, S.; Gao, K.; Yang, X. Volatile Organic Compounds (VOCs) Formation Due to Interactions between Ozone and SkinOiled Clothing: Measurements by Extraction-Analysis-Reaction Method. Build. Environ. 2016, 103, 146-154.

(24) Arata, C.; Heine, N.; Wang, N.; Misztal, P. K.; Wargocki, P.; Bekö, G.; Williams, J.; Nazaroff, W. W.; Wilson, K. R.; Goldstein, A. H. Heterogeneous Ozonolysis of Squalene: Gas-Phase Products Depend on Water Vapor Concentration. Environ. Sci. Technol. 2019, 53, 14441-14448. 
(25) Abbatt, J. P. D.; Wang, C. The Atmospheric Chemistry of Indoor Environments. Environ. Sci.: Processes Impacts 2020, 22, 2548 .

(26) Williams, J.; Brune, W. A Roadmap for $\mathrm{OH}$ Reactivity Research. Atmos. Environ. 2015, 106, 371-372.

(27) Nölscher, A. C.; Yañez-Serrano, A. M.; Wolff, S.; de Araujo, A. C.; Lavrič, J. V.; Kesselmeier, J.; Williams, J. Unexpected Seasonality in Quantity and Composition of Amazon Rainforest Air Reactivity. Nat. Commun. 2016, 7, No. 10383.

(28) Fuchs, H.; Tan, Z.; Lu, K.; Bohn, B.; Broch, S.; Brown, S. S.; Dong, H.; Gomm, S.; Häseler, R.; He, L.; Hofzumahaus, A.; Holland, F.; Li, X.; Liu, Y.; Lu, S.; Min, K.-E.; Rohrer, F.; Shao, M.; Wang, B.; Wang, M.; Wu, Y.; Zeng, L.; Zhang, Y.; Wahner, A.; Zhang, Y. OH Reactivity at a Rural Site (Wangdu) in the North China Plain: Contributions from $\mathrm{OH}$ Reactants and Experimental $\mathrm{OH}$ Budget. Atmos. Chem. Phys. 2017, 17, 645-661.

(29) Zannoni, N.; Gros, V.; Sarda Esteve, R.; Kalogridis, C.; Michoud, V.; Dusanter, S.; Sauvage, S.; Locoge, N.; Colomb, A.; Bonsang, B. Summertime OH Reactivity from a Receptor Coastal Site in the Mediterranean Basin. Atmos. Chem. Phys. 2017, 17, 1264512658 .

(30) Kumar, V.; Chandra, B. P.; Sinha, V. Large Unexplained Suite of Chemically Reactive Compounds Present in Ambient Air Due to Biomass Fires. Sci. Rep. 2018, 8, No. 626.

(31) Whalley, L.; Stone, D.; Heard, D. New Insights into the Tropospheric Oxidation of Isoprene: Combining Field Measurements, Laboratory Studies, Chemical Modelling and Quantum Theory. Top. Curr. Chem. 2014, 339, 55-95.

(32) Pfannerstill, E. Y.; Wang, N.; Edtbauer, A.; Bourtsoukidis, E.; Crowley, J. N.; Dienhart, D.; Eger, P. G.; Ernle, L.; Fischer, H.; Hottmann, B.; Paris, J.-D.; Stönner, C.; Tadic, I.; Walter, D.; Lelieveld, J.; Williams, J. Shipborne Measurements of Total $\mathrm{OH}$ Reactivity around the Arabian Peninsula and Its Role in Ozone Chemistry. Atmos. Chem. Phys. 2019, 19, 11501-11523.

(33) Bekö, G.; Wargocki, P.; Wang, N.; Li, M.; Weschler, C. J.; Morrison, G.; Langer, S.; Ernle, L.; Licina, D.; Yang, S.; Zannoni, N.; Williams, J. The Indoor Chemical Human Emissions and Reactivity (ICHEAR) Project: Overview of Experimental Methodology and Preliminary Results. Indoor Air 2020, 30, 1213-1228.

(34) Wang, N.; Zannoni, N.; Ernle, L.; Bekö, G.; Wargocki, P.; Li, M.; Weschler, C. J.; Williams, J. Total $\mathrm{OH}$ Reactivity of Emissions from Humans: In Situ Measurement and Budget Analysis. Environ. Sci. Technol. 2021, 55, 149-159.

(35) Salvador, C. M.; Bekö, G.; Weschler, C. J.; Morrison, G.; Le Breton, M.; Hallquist, M.; Ekberg, L.; Langer, S. Indoor Ozone/ Human Chemistry and Ventilation Strategies. Indoor Air 2019, 29, 913-925.

(36) Fuchs, H.; Novelli, A.; Rolletter, M.; Hofzumahaus, A.; Pfannerstill, E. Y.; Kessel, S.; Edtbauer, A.; Williams, J.; Michoud, V.; Dusanter, S.; Locoge, N.; Zannoni, N.; Gros, V.; Truong, F.; SardaEsteve, R.; Cryer, D. R.; Brumby, C. A.; Whalley, L. K.; Stone, D.; Seakins, P. W.; Heard, D. E.; Schoemaecker, C.; Blocquet, M.; Coudert, S.; Batut, S.; Fittschen, C.; Thames, A. B.; Brune, W. H.; Ernest, C.; Harder, H.; Muller, J. B. A.; Elste, T.; Kubistin, D.; Andres, S.; Bohn, B.; Hohaus, T.; Holland, F.; Li, X.; Rohrer, F.; KiendlerScharr, A.; Tillmann, R.; Wegener, R.; Yu, Z.; Zou, Q.; Wahner, A. Comparison of $\mathrm{OH}$ Reactivity Measurements in the Atmospheric Simulation Chamber SAPHIR. Atmos. Meas. Tech. 2017, 10, 40234053.

(37) Sinha, V.; Williams, J.; Crowley, J. N.; Lelieveld, J. The Comparative Reactivity Method - a New Tool to Measure Total OH Reactivity in Ambient Air. Atmos. Chem. Phys. 2008, 8, 2213-2227.

(38) Lindinger, W.; Jordan, A. Proton-Transfer-Reaction Mass Spectrometry (PTR-MS): On-Line Monitoring of Volatile Organic Compounds at Pptv Levels. Chem. Soc. Rev. 1998, 27, 347-375.

(39) Atkinson, R.; Aschmann, S. M.; Winer, A. M.; Carter, W. P. L. Rate Constants for the Gas Phase Reactions of $\mathrm{OH}$ Radicals and $\mathrm{O} 3$ with Pyrrole at $295 \pm 1 \mathrm{~K}$ and Atmospheric Pressure. Atmos. Environ. (1967) 1984, 18, 2105-2107.
(40) Dillon, T. J.; Tucceri, M. E.; Dulitz, K.; Horowitz, A.; Vereecken, L.; Crowley, J. N. Reaction of Hydroxyl Radicals with C4H5N (Pyrrole): Temperature and Pressure Dependent Rate Coefficients. J. Phys. Chem. A 2012, 116, 6051-6058.

(41) Zannoni, N.; Dusanter, S.; Gros, V.; Sarda Esteve, R.; Michoud, V.; Sinha, V.; Locoge, N.; Bonsang, B. Intercomparison of Two Comparative Reactivity Method Instruments Inf the Mediterranean Basin during Summer 2013. Atmos. Meas. Tech. 2015, 8, 3851-3865.

(42) Michoud, V.; Hansen, R. F.; Locoge, N.; Stevens, P. S.; Dusanter, S. Detailed Characterizations of the New Mines Douai Comparative Reactivity Method Instrument via Laboratory Experiments and Modeling. Atmos. Meas. Tech. 2015, 8, 3537-3553.

(43) Li, M.; Weschler, C. J.; Bekö, G.; Wargocki, P.; Lucic, G.; Williams, J. Human Ammonia Emission Rates under Various Indoor Environmental Conditions. Environ. Sci. Technol. 2020, 54, 54195428.

(44) Zhao, J.; Zhang, R. Proton Transfer Reaction Rate Constants between Hydronium Ion $(\mathrm{H} 3 \mathrm{O}+)$ and Volatile Organic Compounds. Atmos. Environ. 2004, 38, 2177-2185.

(45) Bourtsoukidis, E.; Helleis, F.; Tomsche, L.; Fischer, H.; Hofmann, R.; Lelieveld, J.; Williams, J. An Aircraft Gas Chromatograph-Mass Spectrometer System for Organic Fast Identification Analysis (SOFIA): Design, Performance and a Case Study of Asian Monsoon Pollution Outflow. Atmos. Meas. Tech. 2017, 10, 50895105.

(46) Du Bois, D.; Du Bois, E. F. A Formula to Estimate the Approximate Surface Area If Height and Weight Be Known. Nutrition 1989, 5, 303-311.

(47) US EPA. National Center for Environmental Assessment, W. D. Exposure Factors Handbook 2011th ed. (Final Report). https:// cfpub.epa.gov/ncea/risk/recordisplay.cfm?deid=236252 (accessed March 12, 2021).

(48) Azen, R.; Budescu, D. V. The Dominance Analysis Approach for Comparing Predictors in Multiple Regression. Psychol. Methods 2003, 8, 129-148.

(49) Azen, R.; Budescu, D. V. Comparing Predictors in Multivariate Regression Models: An Extension of Dominance Analysis. J. Educ. Behav. Stat. 2006, 31, 157-180.

(50) Azen, R.; Budescu, D. V.; Reiser, B. Criticality of Predictors in Multiple Regression. Br. J. Math. Stat. Psychol. 2001, 54, 201-225.

(51) Lakey, P. S. J.; Morrison, G. C.; Won, Y.; Parry, K. M.; von Domaros, M.; Tobias, D. J.; Rim, D.; Shiraiwa, M. The Impact of Clothing on Ozone and Squalene Ozonolysis Products in Indoor Environments. Commun. Chem. 2019, 2, No. 56.

(52) Rai, A. C.; Guo, B.; Lin, C.-H.; Zhang, J.; Pei, J.; Chen, Q. Ozone Reaction with Clothing and Its Initiated VOC Emissions in an Environmental Chamber. Indoor Air 2014, 24, 49-58.

(53) Anderson, S. E.; Franko, J.; Jackson, L. G.; Wells, J. R.; Ham, J. E.; Meade, B. J. Irritancy and Allergic Responses Induced by Exposure to the Indoor Air Chemical 4-Oxopentanal. Toxicol. Sci. 2012, 127, $371-381$.

(54) Wolkoff, P. Indoor Air Pollutants in Office Environments: Assessment of Comfort, Health, and Performance. Int. J. Hyg. Environ. Health 2013, 216, 371-394.

(55) Mitchell, C. S.; Zhang, J. J.; Sigsgaard, T.; Jantunen, M.; Lioy, P. J.; Samson, R.; Karol, M. H. Current State of the Science: Health Effects and Indoor Environmental Quality. Environ. Health Perspect. 2007, 115, 958-964.

(56) Dolgorouky, C.; Gros, V.; Sarda-Esteve, R.; Sinha, V.; Williams, J.; Marchand, N.; Sauvage, S.; Poulain, L.; Sciare, J.; Bonsang, B. Total OH Reactivity Measurements in Paris during the 2010 MEGAPOLI Winter Campaign. Atmos. Chem. Phys. 2012, 12, 9593-9612.

(57) Ren, X. HOx Concentrations and OH Reactivity Observations in New York City during PMTACS-NY2001. Atmos. Environ. 2003, 37, 3627-3637.

(58) Williams, J.; Keßel, S. U.; Nölscher, A. C.; Yang, Y.; Lee, Y.; Yáñez-Serrano, A. M.; Wolff, S.; Kesselmeier, J.; Klüpfel, T.; Lelieveld, J.; Shao, M. Opposite OH Reactivity and Ozone Cycles in the Amazon Rainforest and Megacity Beijing: Subversion of Biospheric 
Oxidant Control by Anthropogenic Emissions. Atmos. Environ. 2016, $125,112-118$.

(59) Zannoni, N.; Gros, V.; Lanza, M.; Sarda, R.; Bonsang, B.; Kalogridis, C.; Preunkert, S.; Legrand, M.; Jambert, C.; Boissard, C.; Lathiere, J. OH Reactivity and Concentrations of Biogenic Volatile Organic Compounds in a Mediterranean Forest of Downy Oak Trees. Atmos. Chem. Phys. 2016, 16, 1619-1636.

(60) Wisthaler, A.; Tamás, G.; Wyon, D. P.; Strøm-Tejsen, P.; Space, D.; Beauchamp, J.; Hansel, A.; Märk, T. D.; Weschler, C. J. Products of Ozone-Initiated Chemistry in a Simulated Aircraft Environment. Environ. Sci. Technol. 2005, 39, 4823-4832. 